\title{
Expression of glucose transporter-1 is correlated with hypoxia-inducible factor $1 \alpha$ and malignant potential in pancreatic neuroendocrine tumors
}

\author{
MINORU FUJINO ${ }^{1}$, SHINICHI AISHIMA ${ }^{2}$, KOJI SHINDO ${ }^{3}$, YASUNORI ODA ${ }^{3}$, KATSUYA MORIMATSU ${ }^{3}$, \\ KOSUKE TSUTSUMI $^{3}$, TAKAO OTSUKA ${ }^{3}$, MASAO TANAKA ${ }^{3}$ and YOSHINAO ODA ${ }^{1}$ \\ ${ }^{1}$ Department of Anatomical Pathology, Graduate School of Medical Sciences, Kyushu University, Fukuoka 812-8582; \\ ${ }^{2}$ Department of Pathology and Microbiology, Faculty of Medicine, Saga University, Saga 849-8501; \\ ${ }^{3}$ Department of Surgery and Oncology, Graduate School of Medical Sciences, Kyushu University, Fukuoka 812-8582, Japan
}

Received May 29, 2015; Accepted July 28, 2016

DOI: $10.3892 / \mathrm{ol} .2016 .5092$

\begin{abstract}
The present study aimed to investigate the prognostic usefulness of the expression of glucose transporter type 1 (GLUT-1) and GLUT-2, hypoxia-inducible factor $1 \alpha$ $(\mathrm{HIF}-1 \alpha)$ and insulin-like growth factor II messenger RNA-binding protein 3 (IMP3) in pancreatic neuroendocrine tumors (pNETs). Immunohistochemical staining for GLUT-1, GLUT-2, HIF-1 $\alpha$ and IMP3 was performed in 70 pNET specimens. The expression of GLUT-1 and HIF-1 $\alpha$ was significantly higher in the World Health Organization grade $2(\mathrm{G} 2)$, neuroendocrine carcinoma cases and mixed-type pNETs compared with the G1 cases. Vessel invasion, a high $\mathrm{Ki}-67$ labeling index and a high mitotic count were significantly more frequent in the GLUT-1- and HIF-1 $\alpha$-positive cases compared with the negative cases. Lymph node metastasis was significantly higher in the GLUT-1-positive cases than in the negative cases. Insulin expression was significantly higher in the IMP3-positive cases than the negative cases. The GLUT-1 expression group experienced a significantly poor disease-free survival rate compared with the negative GLUT-1 expression group. HIF-1 $\alpha$ expression was significantly correlated with poor disease-free survival and overall survival rates. A multivariate analysis revealed that lymph node metastasis was an independent risk factor for disease-free survival in all cases. In the G1/G2 group, tumor size and lymph node metastasis were independent risk factors for disease-free survival.
\end{abstract}

Correspondence to: Professor Yoshinao Oda, Department of Anatomical Pathology, Graduate School of Medical Sciences, Kyushu University, Maidashi 3-1-1, Higashi, Fukuoka 812-8582, Japan

E-mail: oda@surgpath.med.kyushu-u.ac.jp

Key words: glucose transporter type 1, hypoxia-inducible factor $1 \alpha$, neuroendocrine tumor, pancreas, prognosis
Overall, the results suggested that GLUT-1 is a useful prognostic biomarker for pNETs.

\section{Introduction}

Pancreatic neuroendocrine tumors (pNETs) are a rare clinical entity with an annual incidence of 1.09-5.25 cases per million individuals (1), representing a small percentage of all pancreatic neoplasms; however, their incidence is rising $(2,3)$. These tumors are generally slow-growing and exhibit indolent behavior. However, distant metastasis is possible, worsening the prognosis (4).

It is well recognized that compared with non-neoplastic cells, malignant cells exhibit an accelerated metabolism, a high glucose requirement and an increased uptake of glucose. Glucose transporters (GLUTs) facilitate the entry of glucose into cells. GLUTs are passive carriers that function as an energy-independent system to transport glucose down a concentration gradient (5). GLUT type 1 (GLUT-1) is a high-affinity GLUT that is expressed in normal human tissues, including red blood cells, the endothelium of the blood-brain barrier and the placenta $(6,7)$.

GLUT overexpression is frequently observed in cancer, and it is associated with a high metabolism and the rapid growth of cells in often-hypoxic tumor areas (8). Increased levels of GLUT-1 expression have been demonstrated to be associated with a range of carcinomas, including those of the breasts (9), head and neck (10), bladder (11), colorectum (12) and lungs (13), and pulmonary neuroendocrine carcinomas (NECs) (14). GLUT-2 was previously suggested to be overexpressed in hepatic tumors (15), and breast (16) and gastric cancers (17).

It is known that hypoxia-inducible factor 1 (HIF-1) is a master regulator of the transcriptional responses of mammalian cells to hypoxia. HIF-1 plays a critical role in the expression of a number of genes that control angiogenesis, glucose metabolism, cell proliferation, cell survival and metastasis in response to hypoxia $(18,19)$. Elevated expression of HIF-1 $\alpha$ is associated with a poor prognosis in numerous types of solid tumors, including lung, breast, colorectal, brain, pancreatic, ovarian, 
renal and bladder cancer (20). Downstream HIF-1 targets, such as GLUT-1, play critical roles in cellular metabolism and glucose transport, where enhanced glucose metabolism is observed following the upregulation of their respective genes by hypoxia (18).

Insulin-like growth factor II messenger RNA-binding protein 3 (IMP3) plays an important role in RNA trafficking and stabilization, cell growth and cell migration during the early stages of embryogenesis $(21,22)$. The expression of IMP3 is found in malignant tumors as an oncofetal protein that promotes cell proliferation, and the adhesion and invasion of malignant neoplasms (23). IMP3 expression has been studied in neuroendocrine tumors of the lung (24), but to the best of our knowledge, no studies have examined IMP3 expression in pNETs.

It is difficult to evaluate the malignant potential of pNETs, as recurrence or distant metastasis is occasionally observed in the group of low-grade pNETs. The aim of the present study was to clarify the usefulness of the expression of GLUT-1, GLUT-2, HIF-1 $\alpha$ and IMP3 in pNETs, and their clinicopathological correlation for evaluating the malignant potential of pNETs.

\section{Materials and methods}

Case selection. The study used 70 formalin-fixed paraffin-embedded tissue samples of pNETs that had been obtained from surgical resection samples and diagnosed at the Department of Anatomical Pathology (Pathological Science, Graduate School of Medical Science, Kyushu University, Fukuoka, Japan) between June 1991 and May 2011. All samples were classified into four groups according to the World Health Organization classification (2010) (25): G1 (mitotic count of $<2$ and/or $\leq 2 \% \mathrm{Ki}-67$ index; $\mathrm{n}=47$ ), G2 (mitotic count of 2-20 and/or 3-20\% Ki-67 index; $\mathrm{n}=18$ ), NEC (large- or small-cell type; $n=4$ ) and mixed adenoneuroendocrine carcinoma (mixed type, $n=1$ ). Available clinical follow-up data were obtained from 50 of the pNET patients. This study was approved by the Institutional Review Board of Kyushu University and conformed to the ethical guidelines of the 1975 Declaration of Helsinki.

Immunohistochemical staining and evaluation. All specimens were fixed in $10 \%$ formalin and processed routinely. Hematoxylin and eosin staining was also performed on $4-\mu \mathrm{m}$ thick sections of formalin-fixed paraffin-embedded tissue. The sections were deparaffinized in xylene and rehydrated in ethanol. Endogenous peroxidase activity was blocked by incubation in methanol containing $0.3 \% \mathrm{H}_{2} \mathrm{O}_{2}$ for $30 \mathrm{~min}$. Antigen retrieval was achieved by microwave heating in $10 \mathrm{mM}$ citrate buffer (pH 6.0) for 20 min (for GLUT-1 and GLUT-2) or in Target Retrieval Solution (pH 9.0; Dako, Carpinteria, CA) for $20 \mathrm{~min}$ (for IMP3), or through use of BORG Decloaker solution (Biocare Medical, Walnut Creek, CA, USA) and a Decloaking Chamber (Biocare Medical) for $\sim 30 \mathrm{~min}$ (for HIF-1 $\alpha$ ).

The sections were incubated overnight at $4^{\circ} \mathrm{C}$ with the following primary antibodies: Rabbit polyclonal anti-GLUT-1 (1:300 dilution; cat. no. ab15309; Abcam, Cambridge, UK), mouse monoclonal anti-GLUT-2 (1:1,000 dilution; cat. no. ab85715; Abcam), mouse monoclonal anti-HIF-1 $\alpha$ (1:500 dilution; cat. no. NB100-105; Novus Biologicals, Littleton, CO, USA), mouse monoclonal anti-IMP3 (1:100 dilution; cat. no. M3626; Dako) and mouse monoclonal anti-insulin (1:1 dilution; cat. no. ab6995; Abcam). The labeled antigens were detected with an EnVision+ system -Horseradish Peroxidase-Labeled Polymer system (Dako) and visualized using 3,3'-diaminobenzidine tetrahydrochloride as a chromogen. Counterstaining was then performed with hematoxylin.

Samples of clearcell renal cell carcinoma, normal liver tissue, colon cancer and normal tonsil tissue were used as the positive controls of GLUT-1, GLUT-2, HIF-1 $\alpha$ and IMP3, respectively. Immunoreactivities were assessed in the membranous staining for GLUT-1, the cytoplasmic staining for GLUT-2, IMP3 and insulin, and the nuclear staining for HIF-1 $\alpha$, and were defined as positive for any extent of expression. Islets of Langerhans or red blood cells were used as internal controls of GLUT-1 and GLUT-2, respectively. All stained slides were reviewed independently by two pathologists.

Statistical analysis. All statistical analyses were performed using JMP 9.0.2 software (SAS Institute, Cary, NC, USA). Clinicopathological comparisons were conducted using the Pearson, $\chi^{2}$ and Fisher's exact tests. Survival curves were calculated by the Kaplan-Meier method, and the survival data were examined by the log-rank test. $\mathrm{P}<0.05$ was considered to indicate a significant difference.

\section{Results}

GLUT-1, GLUT-2, HIF-1 $\alpha$ and IMP3 expression, and clinicopathological findings. The correlations between the immunohistochemical results and clinicopathological findings are summarized in Table I. In the GLUT-1-positive cases, positive cells were distributed along the periphery to the center of the tumor, accompanied by moderate to severe fibrosis or necrosis. Membranous staining of GLUT-1 was found in 8 out of the $47(17 \%)$ G1 tumors, in 8 out of the $18(44 \%)$ G2 tumors, and in all of the NEC and mixed-type tumors (100\%) (Fig. 1). The expression of GLUT-1 was significantly higher in the G2, NEC and mixed-type cases compared with the $\mathrm{G} 1$ cases $(\mathrm{P}=0.0007)$. Vessel invasion $(\mathrm{P}=0.0007)$, lymph node metastasis $(\mathrm{P}=0.026)$, a high Ki-67 labeling index $(\mathrm{P}=0.0019)$ and high mitotic counts $(\mathrm{P}=0.0002)$ were significantly more frequent in the GLUT-1-positive cases (Table I).

GLUT-2 staining was detected in the cytoplasm of the tumor cells in 4 out of the $47(8.5 \%) \mathrm{Gl}$ cases, in 2 out of the $18(11 \%)$ $\mathrm{G} 2$ cases, in 1 out of the 4 (25\%) NEC cases and in the single (100\%) mixed-type case (Fig. 2A). GLUT-2 expression exhibited no correlation with any clinicopathological factors (Table I).

HIF-1 $\alpha$ expression was detected in the nucleus of the tumor cells in 4 out of the $47(8.5 \%)$ G1 cases, in 4 out of the $18(22 \%)$ G2 cases, in 1 out of the $4(25 \%)$ NEC cases and in the single $(100 \%)$ mixed-type case (Fig. 2B). HIF-1 $\alpha$ expression was also significantly higher in the G2, NEC and mixed-type groups compared with the $\mathrm{G} 1$ group $(\mathrm{P}=0.048)$. The vessel invasion $(\mathrm{P}=0.048)$, high Ki-67 labeling index $(\mathrm{P}=0.012)$ and high mitotic counts $(\mathrm{P}=0.038)$ were each significantly correlated with HIF-1 $\alpha$ expression (Table I). There was a significant 
Table I. Association of GLUT-1, GLUT-2, HIF-1 $\alpha$ and IMP3 expression with clinicopathological variables.

\begin{tabular}{|c|c|c|c|c|c|c|c|c|c|}
\hline \multirow[b]{2}{*}{ Variables } & \multirow[b]{2}{*}{$\mathrm{n}$} & \multicolumn{2}{|c|}{ GLUT-1 } & \multicolumn{2}{|c|}{ GLUT-2 } & \multicolumn{2}{|c|}{ HIF-1 $\alpha$} & \multicolumn{2}{|c|}{ IMP3 } \\
\hline & & $\begin{array}{l}\text { Positive/ } \\
\text { negative }\end{array}$ & P-value & $\begin{array}{l}\text { Positive/ } \\
\text { negative }\end{array}$ & P-value & $\begin{array}{l}\text { Positive/ } \\
\text { negative }\end{array}$ & P-value & $\begin{array}{l}\text { Positive/ } \\
\text { negative }\end{array}$ & P-value \\
\hline Total cases & 70 & $21 / 49$ & & $8 / 62$ & & $10 / 60$ & & $10 / 60$ & \\
\hline Mean age, years & & & 0.3208 & & 0.8634 & & 0.6250 & & 0.6250 \\
\hline$<55$ & 33 & $8 / 25$ & & $4 / 29$ & & $4 / 29$ & & $4 / 29$ & \\
\hline$\geqq 55$ & 37 & $13 / 24$ & & $4 / 33$ & & $6 / 31$ & & $6 / 31$ & \\
\hline Gender & & & 0.6296 & & 0.9473 & & 0.5475 & & 0.4226 \\
\hline Female & 43 & $12 / 31$ & & $5 / 38$ & & $7 / 36$ & & $5 / 38$ & \\
\hline Male & 27 & $9 / 18$ & & $3 / 24$ & & $3 / 24$ & & $5 / 22$ & \\
\hline Tumor size, $\mathrm{cm}$ & & & 0.1244 & & 0.6228 & & 0.4561 & & 1.0000 \\
\hline$\geqq 3.0$ & 21 & $9 / 12$ & & $3 / 18$ & & $4 / 17$ & & $3 / 18$ & \\
\hline$<3.0$ & 49 & $12 / 37$ & & $5 / 44$ & & $6 / 43$ & & $7 / 42$ & \\
\hline Vessel invasion & & & $0.0007^{\mathrm{a}}$ & & 0.7664 & & $0.0484^{\mathrm{a}}$ & & 0.0965 \\
\hline+ & 23 & $13 / 10$ & & $3 / 20$ & & $6 / 17$ & & $1 / 22$ & \\
\hline- & 47 & $8 / 39$ & & $5 / 42$ & & $4 / 43$ & & $9 / 38$ & \\
\hline Lymph node metastasis & & & $0.0261^{\mathrm{a}}$ & & 0.5131 & & 0.4755 & & 0.0745 \\
\hline+ & 15 & $8 / 7$ & & $1 / 14$ & & $3 / 12$ & & $0 / 15$ & \\
\hline- & 55 & $13 / 42$ & & $7 / 48$ & & $7 / 48$ & & $10 / 45$ & \\
\hline Necrosis & & & 0.6903 & & 0.6228 & & 0.4561 & & 0.4561 \\
\hline+ & 21 & $7 / 14$ & & $3 / 18$ & & $2 / 19$ & & $2 / 19$ & \\
\hline- & 49 & $14 / 35$ & & $5 / 44$ & & $8 / 41$ & & $8 / 41$ & \\
\hline Functioning & & & 0.1307 & & 0.4239 & & 0.8399 & & 0.8399 \\
\hline+ & 26 & $5 / 21$ & & $4 / 22$ & & $4 / 22$ & & $4 / 22$ & \\
\hline- & 44 & $16 / 28$ & & $4 / 40$ & & $6 / 38$ & & $6 / 38$ & \\
\hline Insulin & & & 0.8644 & & 0.1896 & & 0.4561 & & $0.0253^{\mathrm{a}}$ \\
\hline+ & 21 & $6 / 15$ & & $4 / 17$ & & $2 / 19$ & & $6 / 15$ & \\
\hline- & 49 & $15 / 34$ & & $4 / 45$ & & $8 / 41$ & & $4 / 45$ & \\
\hline Ki-67 index, \% & & & $0.0019^{\mathrm{a}}$ & & 0.1224 & & $0.0116^{\mathrm{a}}$ & & 0.8263 \\
\hline$>2$ & 19 & $11 / 8$ & & $4 / 15$ & & $6 / 13$ & & $3 / 16$ & \\
\hline$\leqq 2$ & 51 & $10 / 41$ & & $4 / 47$ & & $4 / 47$ & & $7 / 44$ & \\
\hline Mitotic count & & & $0.0002^{\mathrm{a}}$ & & 0.1045 & & $0.0383^{\mathrm{a}}$ & & 0.5174 \\
\hline$\geqq 2$ & 12 & $9 / 3$ & & $3 / 9$ & & $4 / 8$ & & $1 / 11$ & \\
\hline$<2$ & 58 & $12 / 46$ & & $5 / 53$ & & $6 / 52$ & & $9 / 49$ & \\
\hline WHO classification & & & $0.0007^{\mathrm{a}, \mathrm{b}}$ & & $0.2727^{b}$ & & $0.0484^{\mathrm{a}, \mathrm{b}}$ & & $0.8354^{\mathrm{b}}$ \\
\hline G1 & 47 & $8 / 39$ & & $4 / 43$ & & $4 / 43$ & & $7 / 40$ & \\
\hline $\mathrm{G} 2$ & 18 & $8 / 10$ & & $2 / 16$ & & $4 / 14$ & & $2 / 16$ & \\
\hline NEC & 4 & $4 / 0$ & & $1 / 3$ & & $1 / 3$ & & $1 / 3$ & \\
\hline Mixed-type & 1 & $1 / 0$ & & $1 / 0$ & & $1 / 0$ & & $0 / 0$ & \\
\hline
\end{tabular}

${ }^{\mathrm{a}} \mathrm{P}<0.05 .{ }^{\mathrm{b}} \mathrm{G} 1$ compared with G2, NEC and mixed-type. WHO, World Health Organization; G, grade; NEC, neuroendocrine carcinoma; GLUT, glucose transporter; HIF-1 $\alpha$; hypoxia-inducible factor $1 \alpha$; IMP3, insulin-like growth factor II messenger RNA-binding protein 3; functioning, insulinoma, glucagonoma, somatostatinoma, gastrinoma and VIPoma.

correlation between GLUT-1 expression and HIF-1 $\alpha$ expression $(\mathrm{P}=0.025)$ (Table II).

IMP3 expression was recognized in the cytoplasm of the tumor cells. IMP3 was expressed in 7 out of the $47(15 \%)$ G1 cases, in 2 of the $18(11 \%) \mathrm{G} 2$ cases, and in 1 out of the $4(25 \%)$ NEC cases, but not in the single $(0 \%)$ mixed type case.
Insulin expression was significantly more frequently observed in the IMP3-positive cases compared with the IMP3-negative cases $(\mathrm{P}=0.025)$ (Table I).

Survival analysis. Patients in the positive GLUT-1 expression group showed significantly poor disease-free survival 
Table II. Association between HIF-1 $\alpha$ and GLUT-1/GLUT-2.

\begin{tabular}{lccc}
\hline & \multicolumn{3}{c}{ HIF-1 $\alpha$} \\
\cline { 2 - 4 } Expression & $\begin{array}{c}\text { Positive } \\
(\mathrm{n}=10)\end{array}$ & $\begin{array}{c}\text { Negative } \\
(\mathrm{n}=60)\end{array}$ & P-value \\
\hline $\begin{array}{l}\text { GLUT-1 } \\
\text { Positive/negative }\end{array}$ & $6 / 4$ & $15 / 45$ & 0.025 \\
$\begin{array}{l}\text { GLUT-2 } \\
\text { Positive/negative }\end{array}$ & $2 / 8$ & $6 / 54$ & 0.357 \\
\hline
\end{tabular}

GLUT, glucose transporter; HIF-1 $\alpha$; hypoxia-inducible factor $1 \alpha$.
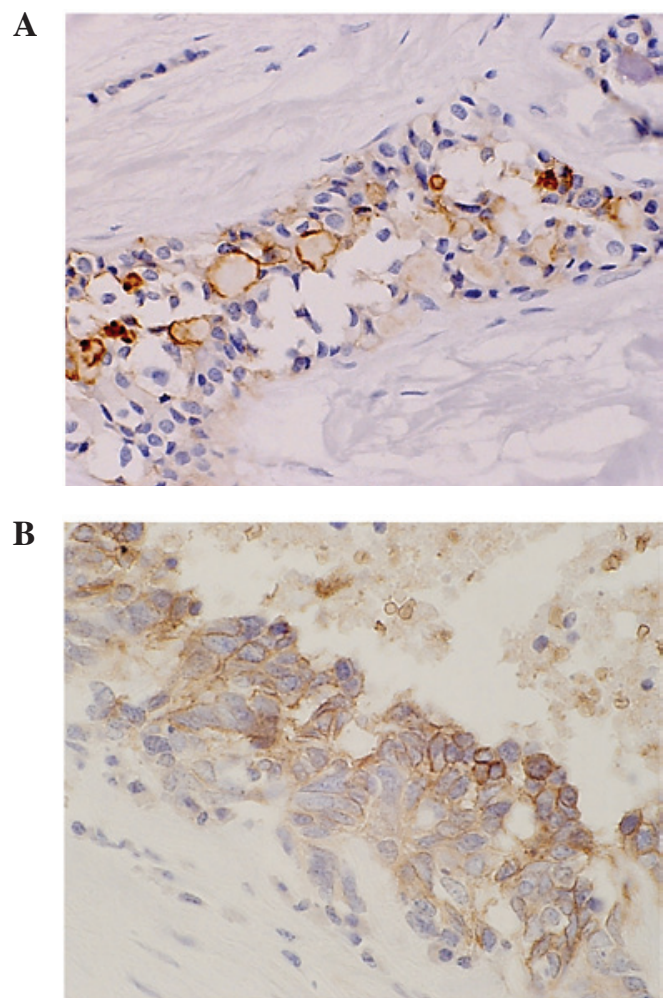

Figure 1. GLUT-1 expression in pancreatic neuroendocrine tumors. GLUT-1 showing a membranous staining pattern in (A) grade 1 and (B) neuroendocrine carcinoma small cell type tumors. Magnification, x400. GLUT-1, glucose transporter type 1 .

rates compared with those in the negative group $(\mathrm{P}=0.0039$; Fig. 3A). Among the G1/G2 tumors, the patients with positive GLUT-1 expression $(n=12)$ showed significantly poor disease-free survival rates compared with those in the negative GLUT-1 expression group $(\mathrm{n}=36)(\mathrm{P}=0.035$; Fig. 3B). The patients with HIF-1 $\alpha$ expression $(n=5)$ showed significantly poor disease-free survival and overall survival rates $(\mathrm{P}=0.047$ and $\mathrm{P}=0.0071$, respectively) (Fig. $3 \mathrm{C}$ and D). GLUT-2 and IMP3 expression did not affect disease-free survival or overall survival rates.

Multivariate analysis. The significant factors revealed by univariate analysis were assessed using a Cox proportional hazard model. A multivariate analysis revealed that lymph
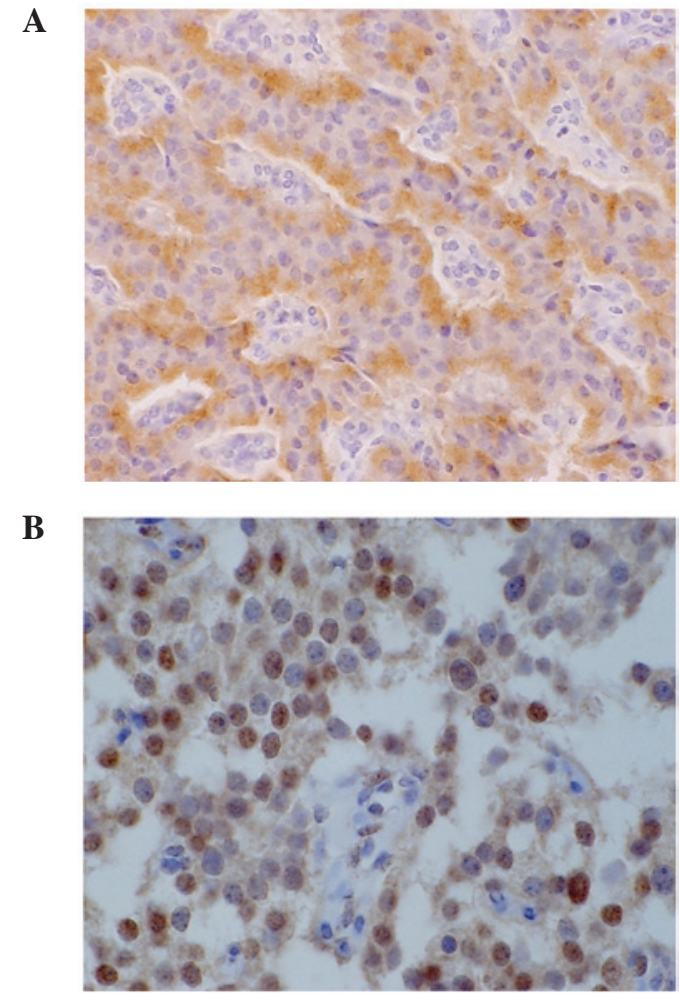

Figure 2. GLUT-2 and HIF-1 $\alpha$ expression in pancreatic neuroendocrine tumors. (A) GLUT-2 showing a cytoplasmic staining pattern in a G1 tumor, and (B) HIF-1 $\alpha$ showing a nuclear staining pattern in a G1 tumor. Magnification, x400. GLUT-2, glucose transporter type 2; HIF1 $\alpha$, hypoxia-inducible factor $1 \alpha$.

node metastasis was an independent risk factor for disease-free survival in all cases $(\mathrm{P}=0.0107)$ (Table III). In the $\mathrm{G} 1 / \mathrm{G} 2$ group, tumor size $(\mathrm{P}=0.0479)$ and lymph node metastasis $(\mathrm{P}=0.0214)$ were shown to be independent risk factors for disease-free survival (Table IV).

\section{Discussion}

Various studies have shown a close association between GLUT-1 expression and tumor aggressiveness and poor prognosis in a number of carcinomas (9-14). However, little is known about GLUT-1 expression in pNETs.

Ozbudak et al demonstrated that GLUT-1 expression was associated with an increased risk of mortality among patients with pulmonary NECs (14), and that GLUT-1 expression was strongly correlated with neuroendocrine differentiation/grade, but not with other clinicopathological variables. In the present study, GLUT-1 expression was similarly significantly increased in the high-grade pNET group. Unlike in the pulmonary NECs, the present pNET cases with GLUT-1 expression were correlated with markers of tumor aggressiveness, including vessel invasion, lymph node metastasis, a high Ki-67 labeling index and a high mitotic count.

These findings indicate that GLUT- 1 expression in pNETs is a more useful marker of malignant potential than that in pulmonary NECs. Moderate to severe fibrosis and/or necrosis is observed in pNETs, suggesting the presence of a hypoxic area in pNETs (17). In response to hypoxia, HIF-1 
Table III. Univariate and multivariate analysis of disease-free survival in all cases.

\begin{tabular}{|c|c|c|c|c|}
\hline \multirow[b]{2}{*}{ Variable } & \multicolumn{2}{|c|}{ Univariate analysis } & \multicolumn{2}{|c|}{ Multivariate analysis } \\
\hline & P-value & Hazard ratio & $95 \%$ confidence interval & P-value \\
\hline Age ( $\geqq 55$ years) & 0.0175 & 0.291 & $0.014-1.822$ & 0.2099 \\
\hline Tumor size $(\geqq 3.0 \mathrm{~cm})$ & 0.0048 & 3.959 & $0.682-33.63$ & 0.1267 \\
\hline Vassel invasion (+) & 0.0012 & 0.381 & $0.020-5.720$ & 0.4891 \\
\hline Lymph node metastasis (+) & $<0.0001$ & 18.591 & $1.797-414.0$ & 0.0107 \\
\hline HIF-1 $\alpha(+)$ & 0.047 & 1.998 & $0.257-11.68$ & 0.4679 \\
\hline GLUT-1 (+) & 0.0078 & 3.081 & $0.458-24.39$ & 0.2490 \\
\hline
\end{tabular}

GLUT, glucose transporter; HIF-1 $\alpha$; hypoxia-inducible factor $1 \alpha$.

Table IV. Univariate and multivariate analysis of disease-free survival in the G1/G2 group.

\begin{tabular}{|c|c|c|c|c|}
\hline \multirow[b]{2}{*}{ Variable } & \multicolumn{2}{|c|}{ Univariate analysis } & \multicolumn{2}{|c|}{ Multivariate analysis } \\
\hline & P-value & Hazard ratio & $95 \%$ confidence interval & P-value \\
\hline Gender (male/female) & 0.0377 & 1.515 & $0.169-16.02$ & 0.7035 \\
\hline Tumor size $(\geqq 3.0 \mathrm{~cm})$ & 0.0302 & 8.328 & $1.018-182.3$ & 0.0479 \\
\hline Vassel invasion (+) & 0.0085 & 0.261 & $0.004-6.712$ & 0.4448 \\
\hline Lymph nodes metastasis $(+)$ & 0.0003 & 32.486 & $1.522-2667$ & 0.0214 \\
\hline $\mathrm{HIF}-1 \alpha(+)$ & 0.3360 & 12.327 & $0.386-459.9$ & 0.1363 \\
\hline GLUT-1 (+) & 0.0509 & 2.436 & $0.354-19.75$ & 0.3654 \\
\hline
\end{tabular}

GLUT, glucose transporter; HIF-1 $\alpha$; hypoxia-inducible factor $1 \alpha$; G, grade.
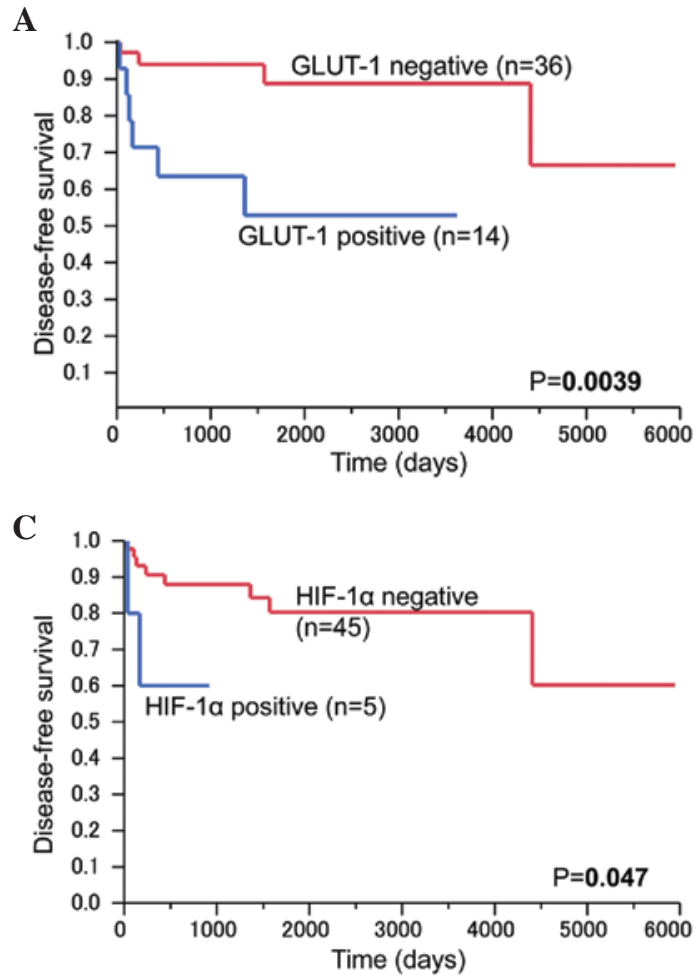
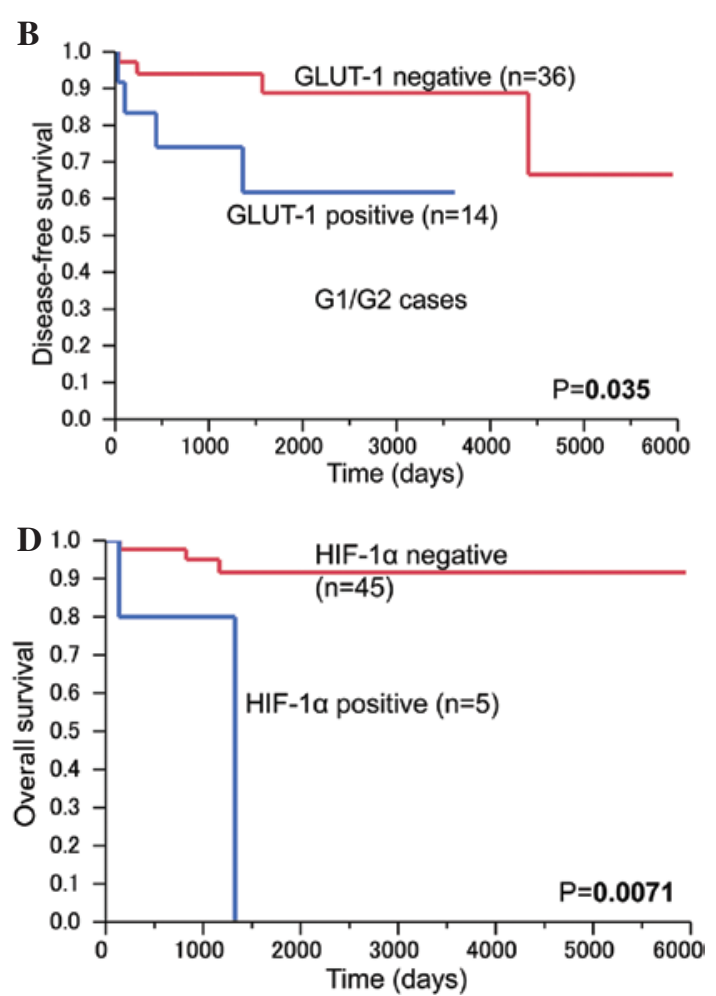

Figure 3. Kaplan-Meier analysis for disease-free survival and overall survival by GLUT-1 and HIF-1 $\alpha$ expression. (A) Among the 50 cases, GLUT-1 expression group showed significantly poor disease-free survival $(\mathrm{P}=0.0039)$. (B) Among the 48 of G1/G2 cases, GLUT-1 expression group showed significantly poor disease-free survival ( $\mathrm{P}=0.035)$. (C) Among the 50 cases, HIF-1 $\alpha$ expression group showed significantly poor disease-free survival ( $\mathrm{P}=0.047)$. (D) Among the 50 cases, HIF-1 $\alpha$ expression group showed significantly poor overall survival $(\mathrm{P}=0.0071)$. 
plays a critical role in the expression of a number of genes that control angiogenesis, cell proliferation, cell survival, metastasis and glucose metabolism. GLUT-1 plays critical roles in cellular metabolism and glucose transport, where enhanced glucose metabolism is observed following the upregulation of their respective genes by hypoxia (17). The present study found that the expression of GLUT-1 was significantly correlated with HIF $1-\alpha$ expression $(\mathrm{P}=0.025)$ in pNETs, indicating the possibility of the induction of GLUT-1 by HIF1- $\alpha$ in the hypoxic condition.

The patients in the present positive GLUT-1 expression group showed significantly poor disease-free survival rates compared with those in the negative GLUT-1 expression group. In addition, the GLUT-1-positive cases in the G1/G2 group showed significantly poor disease-free survival rates $(\mathrm{P}=0.035)$ compared with the negative GLUT-1 expression group. These findings suggest that the expression of GLUT-1 is one of the factors that can be used for the prognostic assessment of pNETs.

Frendrich et al reported that GLUT-2 expression was detectable in normal islet cells and pancreatic intraepithelial neoplasia 1B lesions or higher grade lesions (26). The present study observed the expression of GLUT-2 in normal islet cells, but only in 8 out of the $70(11 \%)$ cases of pNET. These data suggest that elevated glucose metabolism occurs in pNETs via GLUT-1, but not GLUT-2.

IMP3 is expressed in malignant neoplasms, including intraductal papillary mucinous neoplasms (27), pancreatic adenocarcinoma $(28,29)$ and hepatocellular carcinoma $(30)$. In these tumors, IMP3 expression is a useful diagnostic marker for distinguishing the malignant phenotype from benign lesions and is a prognostic biomarker associated with poor survival. The present study showed no association between IMP3 expression and malignant characteristics or prognosis in pNET. However, it was found that GLUT-1 expression is associated with a poor disease-free survival rate, indicating that GLUT-1 is a useful biomarker rather than IMP3 in pNET. Among the 18 cases of insulinoma (18/70; 26\%), 15 cases were positive for insulin; IMP3 expression exhibited a close association with insulin expression, but the mechanism underlying this association is not yet known.

In conclusion, the findings of the present study indicated that GLUT-1 expression is correlated with malignant potential and that its overexpression is a prognostic biomarker for pNET.

\section{Acknowledgements}

The language editing of the original manuscript was performed by KN International (http://www.kninter.com/).

\section{References}

1. Yao JC, Hassan M, Phan A, Dagohoy C, Leary C, Mares JE, Abdalla EK, Fleming JB, Vauthey JN, Rashid A and Evans DB: One hundred years after 'Carcinoid': Epidemiology of and prognostic factors for neuroendocrine tumors in 35,825 cases in the United States. J Clin Oncol 26: 3063-3072, 2008.

2. Yao JC, Eisner MP, Leary C, Dagohoy C, Phan A, Rashid A, Hassan M and Evans DB: Population-based study of islet cell carcinoma. Ann Surg Oncol 14: 3492-3500, 2007.

3. Fitzgerald TL, Hickner ZJ, Schmitz M and Kort EJ: Changing incidence of pancreatic neoplasms: A 16-year review of statewide tumor registry. Pancreas 37: 134-138, 2008.
4. Panzuto F, Boninsegna L, Fazio N, Campana D, Pia Brizzi M, Capurso G, Scarpa A, De Braud F, Dogliotti L, Tomassetti P, et al: Metastatic and locally advances pancreatic endocrine carcinomas: Analysis of factors associated with disease progression. J Clin Oncol 29: 2372-2377, 2011.

5. Macheda ML, Rogers S and Best JD: Molecular and cellular regulation of glucose transporter (GLUT) proteins in cancer. J Cell Physiol 202: 654-662, 2005.

6. Farrell CL, Yang J and Pardridge WM: GLUT-1 glucose transporter is present within apical and basolateral membranes of brain epithelial interfaces and in microvascular endothelia with and without tight junctions. J Histochem Cytochem 40: 193-199, 1992.

7. Mueckler M: Facilitative glucose transporters. Eur J Biochem 219: 713-725, 1994.

8. Clavo AC, Brown RS and Wahl RL: Fluorodeoxyglucose uptake in human cancer cell lines is increased by hypoxia. J Nucl Med 36: 1625-1632, 1995.

9. Kang SS, Chun YK, Hur MH, Lee HK, Kim YJ, Hong SR, Lee JH, Lee SG and Park YK: Clinical significance of glucose transporter 1 (GLUT1) expression in human breast carcinoma. Jpn J Cancer Res 93: 1123-1128, 2002.

10. De Schutter H, Landuyt W, Verbeken E, Goethals L, Hermans R and Nuyts S: The prognostic value of the hypoxia markers CA IX and GLUT 1 and the cytokines VEGF and IL 6 in head and neck squamous cell carcinoma treated by radiotherapy $+/$ - chemotherapy. BMC Cancer 5: 42, 2005.

11. Reis H, Tschirdewahn S, Szarvas T, Rübben H, Schmid KW and Grabellus F: Expression of GLUT1 is associated with increasing grade of malignancy in non-invasive and invasive urothelial carcinomas of the bladder. Oncol Lett 2: 1149-1153, 2011.

12. Wincewicz A, Sulkowska M, Koda M and Sulkowski S: Clinicopathological significance and linkage of the distribution of HIF-1alpha and GLUT-1 in human primary colorectal cancer. Pathol Oncol Res 13: 15-20, 2007.

13. Younes M, Brown RW, Stephenson M, Gondo M and Cagle PT: Overexpression of GLUT1 and GLUT3 in stage I nonsmall cell lung carcinoma is associated with poor survival. Cancer 80: 1046-1051, 1997.

14. Ozbudak IH, Shilo K, Tavora F, Rassaei N, Chu WS, Fukuoka J, Jen J, Travis WD and Franks TJ: Glucose tranporter-1 in pulmonary neuroendocrine carcinomas: Expression and survival analysis. Mod Pathol 22: 633-638, 2009.

15. Wu CH, Ho YS, Tsai CY, Wang YJ, Tseng H, Wei PL, Lee CH, Liu RS and Lin SY: In vitro and in vivo study of phloretin-induced apoptosis in human liver cancer cells involving inhibition of type II glucose transporter. Int J Cancer 124: 2210-2219, 2009.

16. Brown RS and Wahl RL: Overexpression of GLUT-1 glucose transporter in human breast cancer. An immunohistochemical study. Cancer 72: 2979-2985, 1993.

17. Jung JH, Im S, Jung ES and Kang CS: Clinicopathological implications of the expression of hypoxia-related proteins in gastric cancer. Int J Med Sci 10: 1217-1223, 2013.

18. Semenza GL: Hypoxia, clonal selection and the role of HIF-1 in tumor progression. Biochm Mol Biol 35: 71-103, 2000.

19. Semenza GL: Targeting HIF-1 for cancer therapy. Cancer 3: 721-732, 2003.

20. Zhong H, De Marzo AM, Laughner E, Lim M, Hilton DA, Zagzag D, Buechler P, Isaacs WB, Semenza GL and Simons JW: Overexpression of hypoxia-inducible factor 1alpha in common human cancers and their metastases. Cancer Res 59: 5830-5835, 1999.

21. Mueller-Pillasch F, Pohl B, Wilda M, Lacher U, Beil M, Wallrapp C, Hameister H, Knöchel W, Adler G and Gress TM: Expression of the highly conserved RNA binding protein KOC in embryogenesis. Mech Dev 88: 95-99, 1999.

22. Nielsen J, Christiansen J, Lykke-Andersen J, Johnsen AH, Wewer UM and Nielsen FC: A family of insulin-like growth factor II mRNA binding proteins represses translation in late development. Mol Cell Biol 19: 1262-1270, 1999.

23. Liao B, Hu Y, Herrick DJ and Brewer G: The RNA-binding protein IMP-3 is a translational activator of insulin-like growth factor II leader-3 mRNA during proliferation of human K562 leukemia cells. J Biol Chem 280: 18517-18524, 2005.

24. Xu H, Burne PA, Spaulding BO and Wang HL: High-grade neuroendocrine carcinomas of the lung express $\mathrm{K}$ homology domain containing protein overexpressed in cancer but carcinoid tumors do not. Hum Pathol 38: 555-563, 2007. 
25. Klimstra DS, Arnold R, Capella C, Hruban RH, Klöppel G, Komminoth P, Solcia E and Rindi G: Neuroendocrine neoplasms of the pancreas. In: WHO Classification of Tumors of the Digestive System. Bosman FT, Carneiro F, Hruban RH and Theise ND (eds). IARC Press, Lyon, pp322-326, 2010.

26. Frendrich V, Schneider R, Maitra A, Jacobsen ID, Opfermann T and Bartsch DK: Detection of precursor lesions of pancreatic adenocarcinoma in PET-CT in a genetically engineered mouse model or pancreatic cancer. Neoplasisa 13: 180-186, 2011.

27. Morimatsu K, Aishima S, Yamamoto H, Hayashi A, Nakata K, Oda Y, Shindo K, Fujino M, Tanaka M and Oda Y: Insulin-like growth factor II messenger RNA-binding protein-3 is a valuable diagnostic and prognostic marker of intraductal papillary mucinous neoplasm. Hum Pathol 44: 1714-1721, 2013.
28. Schaeffer DF, Owen DR, Lim HJ, Buczkowski AK, Chung SW, Scudamore CH, Huntsman DG, Ng SS and Owen DA: Insulin-like growth factor $2 \mathrm{mRNA}$ binding protein 3 (IGF2BP3) overexpression in pancreatic ductal adenocarcinoma correlates with poor survival. BMC Cancer 10: 59, 2010.

29. Wachter DL, Schlabrakowski A, Hoegel J, Kristiansen G, Hartmann A and Riener MO: Diagnostic value of immunohistochemical IMP3 expression in core needle biopsies of pancreatic ductal adenocarinoma. Am J Surg Patol 35: 873-877, 2011.

30. Jeng YM, Chang CC, Hu FC, Chou HE, Kao HL, Wang TH and Hsu HC: RNA-binding protein insulin-like growth factor II mRNA-binding protein 3 expression promotes tumor invasion and predicts early recurrence and poor prognosis in hepatocellular carcinoma. Hepatology 48: 1118-1127, 2008. 